\title{
Better muscle strength can decrease the risk of arthralgia and back \&joint stiffness in Kurdish men; a cross-sectional study using data from RaNCD cohort study
}

Yahya Pasdar ${ }^{1}$, Behrooz Hamzeh², Shima Moradi ${ }^{3^{*}}$ (D), Sahar Cheshmeh ${ }^{4}$, Farid Najafi ${ }^{5}$, Mehdi Moradinazar ${ }^{6}$, Mohammad Bagher Shamsi ${ }^{7}$ and Ebrahim Shakiba ${ }^{8}$

\begin{abstract}
Background: Musculoskeletal disorders can reduce the quality of life and work capacity. The study assessed handgrip strength (HGS) in relation to low back pain and arthralgia in Kurdish men.

Methods: This cross-sectional study was conducted using data from Ravansar non-communicable diseases (RaNCD) cohort study on 2164 men aged 35-65 years. HGS was measured using a hand-held hydraulic handgrip dynamometer. Low back pain, arthralgia, and joint stiffness were evaluated by the RaNCD cohort study physician using a standard questionnaire.

Results: The results showed that 21.39 and $24.58 \%$ of studied participants had low back pain and arthralgia, respectively. Among the participants with low back pain, 14.5\% had back stiffness, and among those with arthralgia, 12.8\% had joint stiffness. The mean of HGS in participants with arthralgia and back \& joint stiffness was significantly less than those without these disorders $(P<0.001, P=0.05$, and $P=0.005$, respectively). Multiple-adjusted $\mathrm{OR}$ and $95 \%$ confidence intervals (CI) for arthralgia and back and joint stiffness across muscle strength showed the HGS increase to be associated with a lower risk of arthralgia and back \&joint stiffness, but not low back pain.
\end{abstract}

Conclusions: Higher HGS was associated with a lower risk of arthralgia and back \& joint stiffness. However, there was no association between HGS and low back pain. Exercise and adherence to proper nutrition are suggested to enhance muscle strength in order to reduce musculoskeletal pain.

Keywords: Muscle strength, Low back pain, Arthralgia, Back stiffness, Joint stiffness

\footnotetext{
* Correspondence: Shima.Moradi@kums.ac.ir

${ }^{3}$ Department of Nutritional Sciences, Research Center for Environmental Determinants of Health (RCEDH), Health Institute, Kermanshah University of Medical Sciences, Kermanshah, Iran

Full list of author information is available at the end of the article
}

C C The Author(s). 2020 Open Access This article is licensed under a Creative Commons Attribution 4.0 International License, which permits use, sharing, adaptation, distribution and reproduction in any medium or format, as long as you give appropriate credit to the original author(s) and the source, provide a link to the Creative Commons licence, and indicate if changes were made. The images or other third party material in this article are included in the article's Creative Commons licence, unless indicated otherwise in a credit line to the material. If material is not included in the article's Creative Commons licence and your intended use is not permitted by statutory regulation or exceeds the permitted use, you will need to obtain permission directly from the copyright holder. To view a copy of this licence, visit http://creativecommons.org/licenses/by/4.0/. The Creative Commons Public Domain Dedication waiver (http://creativecommons.org/publicdomain/zero/1.0/) applies to the data made available in this article, unless otherwise stated in a credit line to the data. 


\section{Introduction}

One of the most common musculoskeletal problems is low back pain, which affects people's quality of life [1]. Non-specific low back pain is the main cause of back pain; however; low back pain is usually caused by disc herniation, lumbar stenosis, trauma, muscle strain, lumbar spondylosis, spine and kidney infections, certain cancers, endometriosis, arthritis, and ankylosing spondylitis [2, 3]. Results from a systematic review and metaanalysis on 41 studies have shown that the incidence of low back pain is about $25 \%$ among people who have experienced for the first time, without considering community or occupation [4]. In another systematic review and meta-analysis by Fatoye in 2019 on routinely collected data, the incidence range of low back pain has been reported $0.024-7.0 \%$ [5]. It should be noted that since many musculoskeletal disorders are not reported, the number of people with these disorders is much higher in the community [6]. Many studies have reported that the prevalence of musculoskeletal disorders is higher in older men and women than young [6, 7]. However, the peak prevalence of symptoms has been reported between the ages of 40 and 69 [4]. Generally, low back pain is the major reason for immobility, as well as decreased physical function and work capacity that is important, especially in men as the main workforce [2].

Arthralgia, also known as joint pain, is the pain in the area of joints, usually being a subjective symptom of arthritis [8]. Inflammation plays a major role in causing chronic joint pain [9]. In this disorder, joint pain and stiffness occur mainly in the joints of the fingers, wrists, legs, and, in more severe cases, elbows, shoulders, knees, neck, and hip [10].

Handgrip strength (HGS) is a convenient and practical method in clinical and epidemiological studies to reflect musculoskeletal function, and its physical and nutritional status $[11,12]$. This reliable method can reflect overall muscle strength and nutritional status [13]. Optimal muscle strength is associated with a lower risk of noncommunicable diseases (NCDs), such as cardiovascular and diabetes, and overall mortality [11, 14]. According to the high prevalence of musculoskeletal pain, we hypothesize that the recognition of the association between muscle strength and the risk of low back pain and arthralgia could provide suggestions for modifying and improving lifestyle to reduce these pains. Therefore, the present study aims to evaluate the relationship between HGS and the risk of low back pain and arthralgia in Kurdish men in Ravansar noncommunicable diseases (RaNCD) cohort study.

\section{Material and methods}

\section{Study design and setting}

The present cross-sectional study was conducted on baseline data of men enrolled in RaNCD cohort study. The
RaNCD cohort study is the first Kurdish population-based study on 10,059 Kurdish participants (4770 men and 5289 women) aged 35-65 years living in Ravansar city, Kermanshah province, Western- Iran since 2014. It is one of 18 studies developed by the PERSIAN (Prospective Epidemiological Research Studies in Iran) mega cohort study that was approved by the Ethics Committees in the Ministry of Health and Medical Education, the Digestive Diseases Research Institute, Tehran University of Medical Sciences, Iran. The details of this study were described in previous studies $[15,16]$. This cohort study was approved by the Ethics Committee of Kermanshah University of Medical Sciences (No: KUMS.REC.1394.318).

\section{Participants}

Inclusion criteria in this study were men that their muscle strength were measured in the first phase of the RaNCD cohort study. Since muscle mass decreases in cardiovascular diseases, cancer, and thyroid diseases [17-20], we did not include people with these diseases (Fig. 1).

\section{Data sources/measurements \\ Anthropometric indices}

In the study site in Ravansar, InBody 770 device (Inbody Co, Seoul, Korea) was applied to measure the weight of participants with the least clothing and without shoes. In order to measure height, the automatic stadiometer BSM 370 (Biospace Co., Seoul, Korea) was used in a standing position without shoes with a precision of 0.1 $\mathrm{cm}$. Body mass index (BMI) was calculated using this formula: weight $(\mathrm{kg}) /$ (height $^{2}$ (meter) ${ }^{2}$. Waist circumference was measured by non-stretched and flexible tape in standing position at the level of the iliac crest three times, and the average was reported.

\section{Hand grip strength}

A hand-held hydraulic handgrip dynamometer (Model SH5003; SAEHAN Corporation, Masan, Korea) was applied to measure HGS using the dominant hand, while the participant was sitting and the elbow was at $90^{\circ}$ of flexion. The protocol for measuring muscle strength was based on the Southampton method. In this method, the person is asked to sit in a comfortable and standard chair, while the dominant arm is fixed at $90^{\circ}$ on the handle of the chair. In this work, the participants were asked to position the hand so that the thumb was round one side of the handle, and the four fingers were around the other side. After that, the participants were asked to squeeze the handle with maximal effort for $10 \mathrm{~s}$, then dynamometry was repeated after $30 \mathrm{~s}$, and their average was reported as HGS. The calibration of this dynamometer was performed according to the manufacturers' 


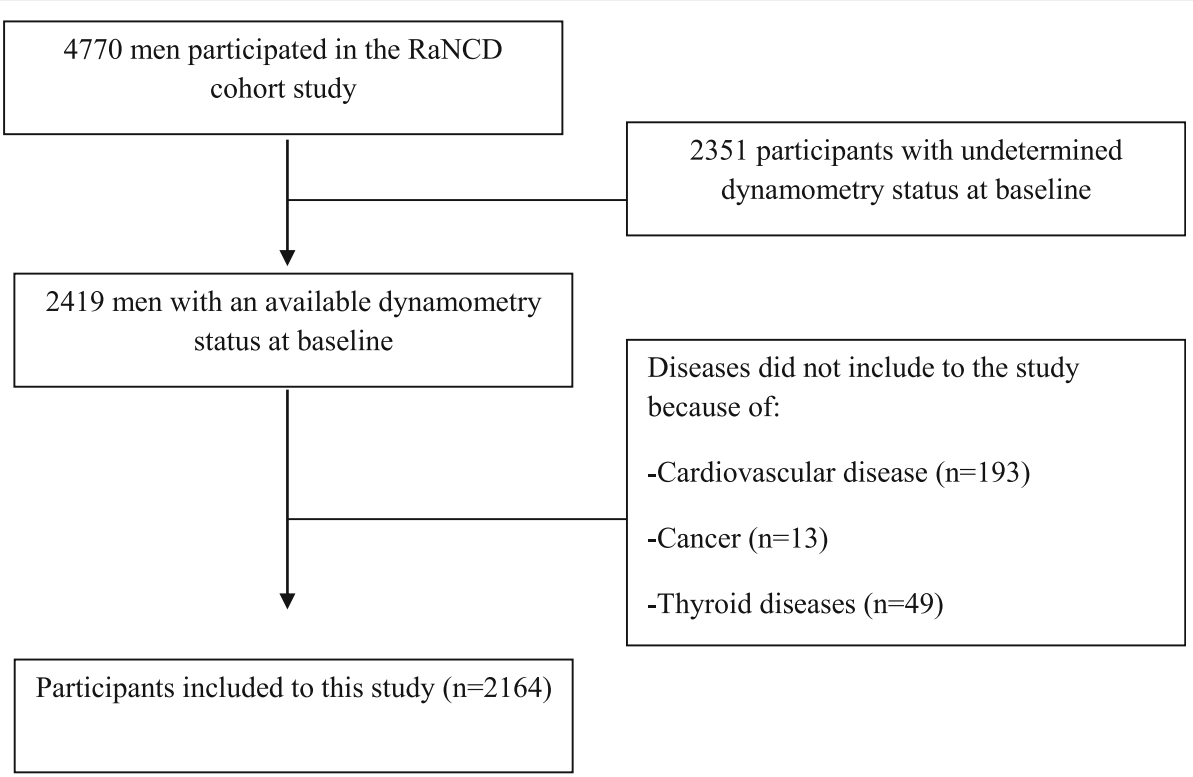

Fig. 1 Flowchart of the samples selection

manual. This device was calibrated at the factory by loading it at the center with weight and making appropriate adjustments in the gauge. The calibration should be checked once a year. If the device is dropped or there is some particular reason to suspect that the calibration is in error, the device should be recalibrated for which it is recommended to be returned to SAEHAN Corporation. The validity and reliability of this device were confirmed by Reis et al. [21].

\section{Outcome measurement}

Low back pain and arthralgia were surveyed using participants' self-reports about pain, as well as the pain area based on the RaNCD cohort study physician opinion and participants' response to her questions as follows: 1) Have you ever had a low back pain lasting more than a week and resulting in serious disruption in your daily activity? (Yes/No); 2) Do you have a history of back stiffness for more than an hour in the morning? (Yes/No); 3) Do you have a history of arthralgia? (Yes/No); 4) Do you have a history of joint stiffness for more than an hour in the morning? (Yes/ No). These questions were administered by the PERSIAN mega cohort study to evaluate chronic diseases in all Iranian adults ages $\geq 35$ years. Then, participants with low back pain and arthralgia were specifically examined by their physician and pain associated with malignancies, infections, and fractures were not considered low back pain. Therefore, the RaNCD cohort study physician diagnosed the type of musculoskeletal pain in the participants based on their medical history and musculoskeletal pain self-report.

\section{Statistical analysis}

Stata, version 14 (Stata Corp, College Station, TX) was applied for all statistical analysis. We compared baseline characteristics of studied participants by Chi-square and independent samples T-test. Quantitative variables were presented as mean \pm standard deviation. Further, qualitative variables were reported using frequency (\%). In order to assess the relationship of muscle strength with back pain and arthralgia, logistic regression was performed to produce odds ratios (OR) for binary outcomes in crude and adjusted models (stepwise). We considered the variables of age and physical activity in adjusted Model 1. Furthermore, in adjusted Model 2, in addition to the variables of Model 1, we controlled the variables of drinking and diabetes. Further, to better illustrate this association, we considered linear regression OR across increased muscle strength with adjustment for the mentioned variables in logistic regression. $P$-values were considered significant at the level of $<0.05$.

\section{Results}

\section{Participants and descriptive data}

In the current study, 2164 of RaNCD participants met the inclusion criteria and thus included in. Weight mean showed no difference in all participants with and without low back pain and arthralgia $(P=0.326$ and 0.87 , respectively). Mean HGS in participants without arthralgia was significantly higher than those with $(P<0.001)$, while there was no HGS difference in participants with and without low back pain $(\mathrm{P}=0.326) .21 .39$ and $24.58 \%$ of studied participants reported low back pain and arthralgia. Among the participants with low back pain, 
14.5\% had back stiffness, and among those with arthralgia, $12.8 \%$ had joint stiffness. The baseline characteristics of the studied participants are presented in Table 1.

\section{Main results}

Figure 2 shows that HGS mean in participants with arthralgia and back \& joint stiffness is significantly less than that in those without these disorders $(\mathrm{P}<0.001, P=0.05$, and $P=0.005$, respectively).

Multiple-adjusted OR and 95\% confidence intervals (CI) for arthralgia and back \& joint stiffness across muscle strength showed that increasing HGS was associated with a lower risk of their occurrence (Table 2). These associations remained after adjusting for potential confounders, including age, physical activity, drinking, and diabetes. According to the findings, participants with better HGS were $2 \%$ less likely to have arthralgia. Better muscle strength was also associated with a 3 and $4 \%$ reduced risk of back and joint stiffness (Table 2).

Moreover, results from multivariable logistic regression showed that risk of back pain, arthralgia, as well as back and joint stiffness, decreased with increasing HGS after adjusting for potential confounders, as shown in Fig. 3.

\section{Discussion}

Our findings revealed that higher HGS could decrease the risk of arthralgia, as well as back and joint stiffness. Indeed, HGS is a general result of the strength of the body used in epidemiological studies [11, 22]. Although the prevalence of musculoskeletal pain in men is lower than women, men are affected by comorbidities associated with these chronic pains as well, leading them to risky behaviors to suppress pain, such as the use of narcotic drugs [23]. Low muscle strength can predict frailty, sarcopenia, falls, fractures, and overall reduced quality of life [12, 24]. HGS is a valid and reliable method for determining the maximum hand muscle strength that shows overall muscle strength and nutritional status [13]. Since musculoskeletal pain is associated with disability and inactivity, recognizing the link between muscle strength and these chronic pains can be an appropriate strategy to reduce it. Furthermore, daily and occupational activity may be restricted by musculoskeletal pain.

In the present study, no association between low back pain and HGS was observed. However, higher HGS was associated with a lower risk of stiffness. AlperovitchNajenson et al. [25] observed that women working in an industrial environment with musculoskeletal pain had low HGS. A study on old women without physical activity showed low HGS to be related to a higher risk of low back pain $(P=0.004)$ [13]. Hershkovitz et al. [22], in their research, indicated that higher HGS was associated with better rehabilitation in patients with hip fracture. Ishak et al. observed that women with low back pain had poorer HGS compared to those of healthy $(P=0.04)$, while they did not find any association between HGS and low back pain in men $(P=0.834)$ [26]. Findings of another cross-sectional study showed a relationship between muscle strength and low back pain in female health care staff, although this pain did not limit their work activity [27]. A clinical trial designed by Han et al. [28] showed that increased muscle strength in lumbar after intervention by aquatic exercise significantly reduced low back pain in older women. Results of a metaanalysis by de Sousa on 14 studies showed the strength of hip abductors, hip extensors, and knee extensor muscles in patients with low back pain to be significantly lower than healthy participants; however, there was no difference in knee flexor muscle strength in patients with low back pain and healthy participants [29]. In the

Table 1 Baseline characteristics of studied participants

\begin{tabular}{|c|c|c|c|c|c|c|c|}
\hline Variables & $\begin{array}{l}\text { Total } \\
(n=2164)\end{array}$ & $\begin{array}{l}\text { Without low back pain } \\
(n=1701)\end{array}$ & $\begin{array}{l}\text { With low back pain } \\
(n=463)\end{array}$ & $P^{* *}$ & $\begin{array}{l}\text { Without arthralgia } \\
(n=1632)\end{array}$ & $\begin{array}{l}\text { With arthralgia } \\
(n=532)\end{array}$ & $P^{* *}$ \\
\hline Age (year) & $46.77 \pm 7.89^{a}$ & $46.53 \pm 7.86$ & $47.63 \pm 7.91$ & 0.006 & $46.21 \pm 7.71$ & $48.48 \pm 8.17$ & $<0.001$ \\
\hline Weight (kg) & $75.44 \pm 13.31$ & $75.31 \pm 13.23$ & $75.92 \pm 13.61$ & 0.326 & $75.38 \pm 13.10$ & $75.63 \pm 13.95$ & 0.87 \\
\hline $\mathrm{BMI}\left(\mathrm{kg} / \mathrm{m}^{2}\right)$ & $25.94 \pm 4.07$ & $25.96 \pm 4.02$ & $25.91 \pm 4.25$ & 0.05 & $25.87 \pm 4.04$ & $26.15 \pm 4.16$ & 0.432 \\
\hline WC $(\mathrm{cm})$ & $96.32 \pm 9.73$ & $96.35 \pm 9.2$ & $96.22 \pm 11.46$ & 0.505 & $96.06 \pm 9.81$ & $97.12 \pm 9.43$ & 0.03 \\
\hline Muscle strength $(\mathrm{kg})$ & $41.15 \pm 9.27$ & $41.23 \pm 9.24$ & $40.83 \pm 9.42$ & 0.326 & $41.69 \pm 9.17$ & $39.47 \pm 9.4$ & $<0.001$ \\
\hline PA (MET hour/day) & $43.21 \pm 9.65$ & $43.27 \pm 9.77$ & $43.01 \pm 9.18$ & 0.893 & $43.17 \pm 9.63$ & $43.34 \pm 9.71$ & 0.472 \\
\hline Drinking, \% & 13.7 & 13.6 & 14 & 0.436 & 13 & 16 & 0.05 \\
\hline Diabetes, \% & 6.3 & 6.6 & 5.4 & 0.218 & 5.8 & 7.9 & 0.05 \\
\hline Back stiffness, $\%$ & 5.1 & 2.5 & 14.5 & $<0.001$ & 2.6 & 12.8 & $<0.001$ \\
\hline Joint stiffness, $\%$ & 3 & 2.1 & 6 & $<0.001$ & 0.4 & 10.9 & $<0.001$ \\
\hline
\end{tabular}

BMI Body mass index, WC Waist circumference, PA Physical activity

${ }^{*}$ P -values were obtained independent samples $T$ test and $C h i$ square

${ }^{\mathrm{a}}$ Mean \pm SD 


\section{$\boldsymbol{\nabla N o} \mathbf{c}$ 'Yes}

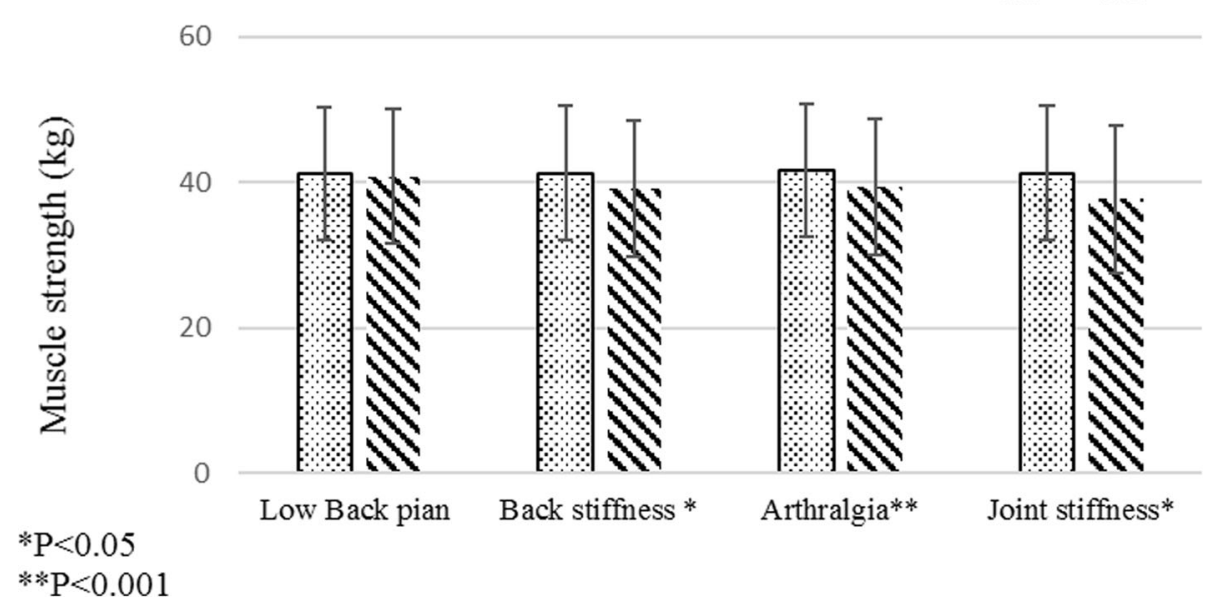

Fig. 2 Differences of muscle strength in participants with low back pain, back stiffness, arthralgia, and joint stiffness and without of all them ${ }^{*} P=$ $0.326 ; P=0.05 ; P<0.001 ;$ and $P=0.005$, respectively)

present study, we found no difference in weight, level of physical activity, diabetes, and alcohol consumption in participants with and without back pain. It seems that the lack of HGS difference in participants with and without back pain is due to the effect of these factors, which is similar in both groups. Another possible reason for the lack of association between low back pain and HGS appears to be that people do their daily activities regardless of the pain in the lower back, especially in men.

The results of this study showed that HGS of participants with arthralgia and joint stiffness was significantly low compared to healthy participants. Terauchi et al. [30], in a survey of middle-aged women, showed that a greater HGS was associated with lower muscle and joint pains (OR: 0.92; CI 95\%: 0.87-0.97). Forechi et al. [24] observed that patients with post-chikungunya chronic arthralgia had significantly lower HGS than adults without this disorder $(P<0.001)$. Findings of a prospective study on young men showed that decreased muscle strength was not associated with an increased risk of fracture musculoskeletal pain. However, after 17 years of

Table 2 Relationship between muscle strength and back and arthralgia

\begin{tabular}{|c|c|c|c|c|}
\hline & Low back pain & $P$ & Arthralgia & $\mathbf{P}$ \\
\hline Crude & $0.99(0.98-1)$ & 0.371 & $0.97(0.96-0.98)$ & $<0.001$ \\
\hline Model $1^{\mathrm{a}}$ & $1(0.99-1.01)$ & 0.744 & $0.98(0.97-0.99)$ & 0.012 \\
\hline Model $2^{b}$ & $1(0.98-1.01)$ & 0.796 & $0.98(0.97-0.99)$ & 0.008 \\
\hline Crude & Back stiffness & $\mathbf{P}$ & Joint stiffness & $\mathbf{P}$ \\
\hline Model $1^{\text {a }}$ & $0.97(0.95-0.99)$ & 0.013 & $0.95(0.93-0.98)$ & 0.002 \\
\hline \multirow[t]{2}{*}{ Model $2^{b}$} & $0.98(0.96-1)$ & 0.098 & $0.97(0.94-1)$ & 0.077 \\
\hline & $0.97(0.95-0.99)$ & 0.048 & $0.96(0.93-0.99)$ & 0.049 \\
\hline
\end{tabular}

${ }^{a}$ Model 1 adjusted for age and physical activity

${ }^{\mathrm{b}}$ Model 2 adjusted for variables in model 1, drinking, and diabetes follow-up, musculoskeletal pain was less reported in people with better muscle strength [31].

With aging, the balance between antioxidant capacity and the production of radical oxygen species is disturbed [32, 33]. Further, systemic inflammation, like what occurs in arthritis and other chronic musculoskeletal pain, results in producing inflammatory cytokines, such as plasma interleukin 6 and tumor necrosis factor-alpha [33]. Poor muscle strength may be induced by oxidative stress and inflammatory cytokines production [32]. Excess radical oxygen species and inflammatory cytokines contribute to activating muscle proteases, leading to protein breakdown [32]. Overall, poor muscle strength increases age-related problems, including falls, disability, and mortality [34].

Some studies have divided the stages of the low back pain based on self-report pain intensity into chronic, acute, and subacute. However, they have not evaluated the relationship between muscle strength and stages of low back pain [35-37]. In the RaNCD cohort study, pain intensity was not assessed, and we were unable to perform this classification. However, our findings indicated that optimal HGS could decrease the risk of arthralgia, back pain, and joint stiffness in the Kurdish men population.

\section{Limitations}

This present study was the first on a large sample size in Kurdish men to evaluate HGS and the risk of low back pain and arthralgia. However, this study suffered from several limitations. First, the degree and severity of pain in the cohort study were not measured. Second, this was a cross-sectional study; therefore, it is not possible to infer that increased HGS causes arthralgia, back pain, and joint stiffness or contrariwise. Since our study was 


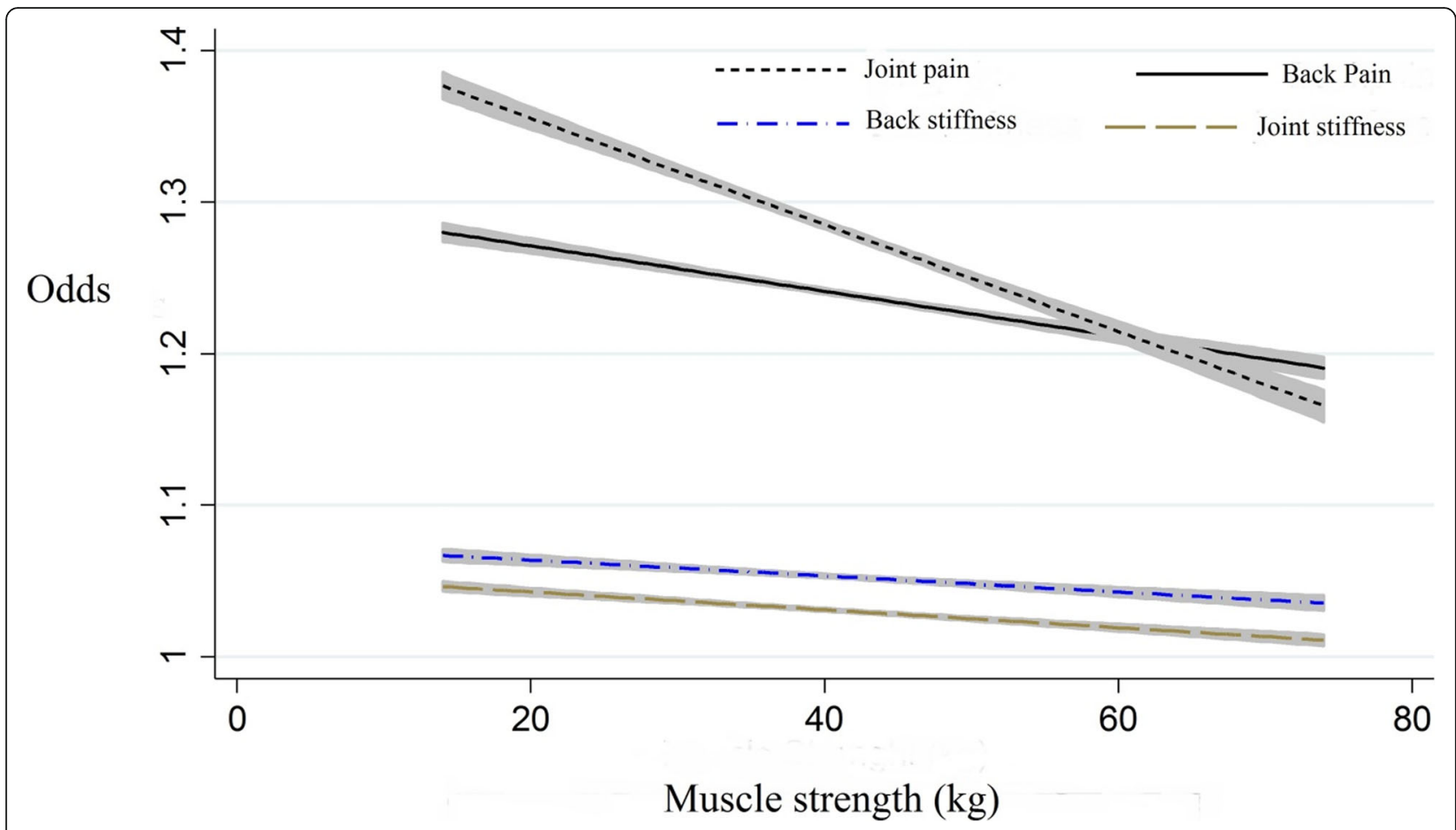

Fig. 3 Liner regression between muscle strength and low back pain and arthralgia

conducted only on men, its findings cannot be generalized to society as a whole. Also, the method of evaluating the outcome was self-reporting and can interfere with the findings. Therefore, further studies are necessary without these limitations.

\section{Conclusions}

To sum up, our findings highlighted that better HGS was associated with a lower risk of arthralgia, as well as back and joint stiffness among Kurdish men. However, these findings did not support the role of muscle strength in low back pain. Nevertheless, after controlling for potential confounders, we did not observe any association between muscle strength and low back pain.

\section{Abbreviations}

HGS: Handgrip strength; NCDs: non-communicable diseases;

RaNCD: Ravansar non- communicable diseases; PERSIAN: Prospective Epidemiological Research Studies in Iran; BMl: Body mass index; OR: odds ratios; $\mathrm{Cl}$ : confidence intervals

\section{Acknowledgments}

RaNCD is part of PERSIAN national cohort and we would like to thank Professor Reza Malekzadeh, Deputy of Research and Technology at the Ministry of Health and Medical Education of Iran and Director of the PERSIAN cohort, and also Dr. Hossein Poustchi Executive Director of PERSIAN cohort for all their supports during design and running of RaNCD.

\section{Informed consent}

Written informed consent was obtained from each studied subject after explaining the purpose of the study. The right of subjects to withdraw from the study at any time and subject's information is reserved and will not be published.

\section{Authors' contributions}

SM and YP equally contributed to the conception and design of the research; FN, BH, ES contributed to data collection; SM, YP and MM contributed to the acquisition and analysis of the data; SM, YP and MS contributed to the interpretation of the data; and SM, MS, SC and YP contributed to draft the manuscript. All authors are in agreement with the manuscript and declare that the content has not been published elsewhere. The author (s) read and approved the final manuscript.

\section{Funding}

This study was supported by Ministry of Health and Medical Education of Iran and Kermanshah University of Medical Science (Grant No: 92472).

\section{Availability of data and materials}

Data will be available upon request from the corresponding author.

\section{Ethics approval and consent to participate}

All procedures performed in studies involving human participants were in accordance with the ethical standards of the institutional and/or national research committee and with the 1964 Helsinki declaration and its later amendments or comparable ethical standards. This study was approved by the Ethics Committee of Kermanshah University of Medical Sciences (ethics approval number: KUMS.REC.1394.318).

\section{Consent for publication}

Not applicable.

\section{Competing interests}

All authors have no conflict of interest.

\section{Author details}

'Department of Nutritional Sciences, Research Center for Environmental Determinants of Health (RCEDH), Health Institute, Kermanshah University of Medical Sciences, Kermanshah, Iran. ${ }^{2}$ School of Public Health, Research 
Center for Environmental Determinates of Health (RCEDH), Kermanshah University of Medical Sciences, Kermanshah, Iran. ${ }^{3}$ Department of Nutritional Sciences, Research Center for Environmental Determinants of Health (RCED H), Health Institute, Kermanshah University of Medical Sciences, Kermanshah, Iran. ${ }^{4}$ Student of Research Committee, School of Nutritional Sciences and Food Technology, Kermanshah University of Medical Sciences, Kermanshah, Iran. ${ }^{5}$ School of Public Health, Communing Developmental and Health Promotion Research center, Kermanshah University of Medical Sciences, Kermanshah, Iran. ${ }^{6}$ Behavioral Disease Research Center, Kermanshah University of Medical Sciences, Kermanshah, Iran. ${ }^{7}$ Rehabilitation and Sports Medicine Department, Kermanshah University of Medical Sciences, Kermanshah, Iran. ${ }^{8}$ Social Development and Health Promotion Research Center, Kermanshah University of Medical Sciences, Kermanshah, Iran.

\section{Received: 8 June 2020 Accepted: 12 October 2020} Published online: 16 October 2020

\section{References}

1. Tagliaferri SD, Miller CT, Owen PJ, Mitchell UH, Brisby H, Fitzgibbon B, Masse-Alarie H, Van Oosterwijck J, Belavy DL. Domains of chronic low back pain and assessing treatment effectiveness: a clinical perspective. Pain Pract. 2020;20:211-25 https://doi.org/10.1111/papr.12846.

2. Garg A, Pathak H, Churyukanov MV, Uppin RB, Slobodin TM. Low back pain: critical assessment of various scales. Eur Spine J. 2020;29:503-18 https://doi. org/10.1007/s00586-019-06279-5.

3. Park S-M, Kim G-U, Kim H-J, Kim H, Chang B-S, Lee C-K, Yeom JS. Walking more than 90 minutes/week was associated with a lower risk of selfreported low back pain in persons over 50years of age: a cross-sectional study using the Korean National Health and nutrition examination surveys. Spine. 2019;19:846-52 https://doi.org/10.1016/j.spinee.2018.11.007.

4. Taylor JB, Goode AP, George SZ, Cook CE. Incidence and risk factors for firsttime incident low back pain: a systematic review and meta-analysis. Spine J. 2014;14:2299-319 https://doi.org/10.1016/j.spinee.2014.01.026.

5. Fatoye F, Gebrye T, Odeyemi I. Real-world incidence and prevalence of low back pain using routinely collected data. Rheumatol Inter. 2019;39:619-26 https://doi.org/10.1007/s00296-019-04273-0.

6. Shamsi M, Safari A, Samadzadeh S, Yoosefpour N. The prevalence of musculoskeletal pain among above 50-year-old population referred to the Kermanshah-Iran health bus in 2016. BMC Res Notes. 2020;13:72 https://doi. org/10.1186/s13104-020-4940-6

7. Meucci RD, Fassa AG, Faria NMX. Prevalence of chronic low back pain: systematic review. Rev Saude Publica. 2015;49:73 https://doi.org/10.1590/ S0034-8910.2015049005874.

8. Dai L, Zeng R. Arthralgia. In: Handbook of Clinical Diagnostics. Springer. 2019; pp 85-86. https://doi.org/10.1007/978-981-13-7677-1_29.

9. Schaible H-G, Richter F, Ebersberger A, Boettger MK, Vanegas H, Natura G, et al. Joint pain. Exp Brain Res. 2009;196:153-62 https://doi.org/10.1007/ s00221-009-1782-9.

10. Zhang A, Lee YC. Mechanisms for joint pain in rheumatoid arthritis (RA): from cytokines to central sensitization. Curr Osteoporos Rep. 2018;16(5):60310 https://doi.org/10.1007/s11914-018-0473-5.

11. Malhotra R, Tareque MI, Tan NC, Ma S. Association of baseline hand grip strength and annual change in hand grip strength with mortality among older people. Arch Gerontol Geriatr. 2020;86:103961 https://doi.org/10.1016/ j.archger.2019.103961.

12. Mehmet $H$, Yang AW, Robinson SR. Measurement of hand grip strength in the elderly: a scoping review with recommendations. J Bodyw Mov Ther. 2020;24:235-43 https://doi.org/10.1016/j.jbmt.2019.05.029.

13. Park S-M, Kim G-U, Kim H-J, Kim H, Chang B-S, Lee C-K, Yeom JS. Low handgrip strength is closely associated with chronic low back pain among women aged 50 years or older: a cross-sectional study using a national health survey. PLoS One. 2018;13 https://doi.org/10.1371/journal.pone. 0207759.

14. Pasdar Y, Moradi S, Moradinazar M, Hamzeh B, Najafi F. Better muscle strength with healthy eating. Eat Weight Disord. 2020; https://doi.org/10, 1007/s40519-020-00863-1.

15. Pasdar Y, Najafi F, Moradinazar M, Shakiba E, Karim H, Hamzeh B, Nelson M, Dobson A. Cohort profile: Ravansar non-communicable disease cohort study: the first cohort study in a Kurdish population. Int J Epidemiol. 2019; https://doi.org/10.1093/ije/dyy296.
16. Poustchi H, Eghtesad S, Kamangar F, Etemadi A, Keshtkar A-A, Hekmatdoost A, Mohammadi Z, Mahmoudi Z, Shayanrad A, Roozafzai F. Prospective epidemiological research studies in Iran (the PERSIAN cohort study): rationale, objectives, and design. Am J Epidemiol. 2017;187:647-55 https://doi.org/10.1093/aje/kwx314.

17. Brennan MD, Powell C, Kaufman KR, Sun PC, Bahn RS, Nair KS. The impact of overt and subclinical hyperthyroidism on skeletal muscle. Thyroid. 2006;16: 375-80 https://doi.org/10.1089/thy.2006.16.375.

18. Fearon K, Strasser F, Anker SD, Bosaeus I, Bruera E, Fainsinger RL, Jatoi A Loprinzi C, MacDonald N, Mantovani G. Definition and classification of cancer cachexia: an international consensus. Lancet Oncol. 2011;12:489-95 https://doi.org/10.1016/S1470-2045(10)70218-7.

19. Lipkin DP, Jones DA, Round JM, Poole-Wilson PA. Abnormalities of skeletal muscle in patients with chronic heart failure. Int J Cardiol. 1998;18:187-95 https://doi.org/10.1016/0167-5273(88)90164-7.

20. Reuters VS, Patrícia de Fátima ST, Vigário PS, Almeida CP, Buescu A, Ferreira MM, Vaisman M, de Castro CL, Gold J. Functional capacity and muscular abnormalities in subclinical hypothyroidism. Am J Med Sci. 2009;338:259-63 https://doi.org/10.1097/MAJ.0b013e3181af7c7c.

21. Reis MM, Arantes PMM. Assessment of hand grip strength-validity and reliability of the saehan dynamometer. Fisioterapia e Pesquisa. 2011;18(2): 176-81 https://doi.org/10.1590/S1809-29502011000200013.

22. Hershkovitz A, Yichayaou B, Ronen A, Maydan G, Kornyukov N, Burstin A, Brill S. The association between hand grip strength and rehabilitation outcome in post-acute hip fractured patients. Aging Clin Exp Res. 2019;31: 1509-16 https://doi.org/10.1007/s40520-019-01200-y.

23. Bento TPF, dos Santos Genebra CV, Maciel NM, Cornelio GP, Simeão SFAP, de Vitta A. Low back pain and some associated factors: is there any difference between genders? Braz J Phys Ther. 2020;24:79-87 https://doi. org/10.1016/j.bjpt.2019.01.012.

24. Forechi L, Silveira-Nunes G, Barbosa MA, Barbosa ÉG, Santos DLd, Vieira ER, et al. Pain, balance, grip strength and gait parameters of older adults with and without post-chikungunya chronic arthralgia. Trop Med Int Health. 2018;23:1394-400. https://doi.org/10.1111/tmi.13154.

25. Alperovitch-Najenson D, Carmeli E, Coleman R, Ring H. Handgrip strength as a diagnostic tool in work-related upper extremity musculoskeletal disorders in women. ScientificWorld Journal. 2004;4:111-7 https://doi.org/10. 1100/tsw.2004.12

26. Ishak N, Zahari Z, Justine M. Muscle functions and functional performance among older persons with and without low Back pain. Curr Gerontol Geriatr Res. 2016;2016:8583963 https://doi.org/10.1155/2016/8583963.

27. Moberg LL, Lunde L-K, Koch M, Tveter AT, Veiersted KB. Association between VO 2 max, handgrip strength, and musculoskeletal pain among construction and health care workers. BMC Public Health. 2017;17:272 https://doi.org/10.1186/s12889-017-4173-3.

28. Han G, Cho M, Nam G, Moon T, Kim J, Kim S, et al. The effects on muscle strength and visual analog scale pain of aquatic therapy for individuals with low back pain. J Phys Ther Sci. 2011;23(1):57-60 https://doi.org/doi.org/10.15 89/jpts.23.57.

29. de Sousa CS, de Jesus FLA, Machado MB, Ferreira G, Ayres IGT, de Aquino LM, Fukuda TY, Gomes-Neto M. Lower limb muscle strength in patients with low back pain: a systematic review and meta-analysis. J Musculoskelet Neuronal Interact. 2019;19:69-78.

30. Terauchi M, Odai T, Hirose A, Kato K, Akiyoshi M, Miyasaka N. Muscle and joint pains in middle-aged women are associated with insomnia and low grip strength: a cross-sectional study. J Psychosom Obstet Gynaecol. 2020; 41:15-21 https://doi.org/10.1080/0167482X.2018.1530211.

31. Timpka S, Petersson IF, Zhou C, Englund M. Muscle strength in adolescent men and future musculoskeletal pain: a cohort study with 17 years of follow-up. BMJ Open. 2013;3 https://doi.org/10.1136/bmjopen-2013-002656.

32. Gomes MJ, Martinez PF, Pagan LU, Damatto RL, Cezar MDM, Lima ARR, Okoshi K, Okoshi MP. Skeletal muscle aging: influence of oxidative stress and physical exercise. Oncotarget. 2017:8:20428-40 https://doi.org/10. 18632/oncotarget.14670.

33. González-Bartholin R, Mackay K, Valladares D, Zbinden-Foncea H, Nosaka K, Peñailillo L. Changes in oxidative stress, inflammation and muscle damage markers following eccentric versus concentric cycling in older adults. Eur J Appl Physiol. 2019;119:2301-12 https://doi.org/10.1007/s00421-019-04213-7.

34. Felício DC, Diz JBM, Pereira DS, de Queiroz BZ, de Silva JP, de Souza MB, Oliveira VC, Pereira LSM. Handgrip strength is associated with, but poorly predicts, disability in older women with acute low back pain: a 12-month 
follow-up study. Maturitas. 2017;104:19-23 https://doi.org/10.1016/j. maturitas.2017.07.006.

35. Hüllemann P, Keller T, Kabelitz M, Gierthmühlen J, Freynhagen R, Tölle T, et al. Clinical manifestation of acute, subacute, and chronic low back pain in different age groups: low back pain in 35,446 patients. Pain Pract. 2018;18: 1011-23 https://doi.org/10.1111/papr.12704.

36. Apeldoorn AT, Bosmans JE, Ostelo RW, de Vet HC, van Tulder MW. Costeffectiveness of a classification-based system for sub-acute and chronic low back pain. Eur Spine J. 2012;21(7):1290-300 https://doi.org/10.1007/s00586011-2144-4.

37. Brox Jl, Storheim K, Holm I, Friis A, Reikeras O. Disability, pain, psychological factors and physical performance in healthy controls, patients with subacute and chronic low back pain: a case-control study. J Rehabil Med. 2005: 37(2):95-9 https://doi.org/10.1080/16501970410017738.

\section{Publisher's Note}

Springer Nature remains neutral with regard to jurisdictional claims in published maps and institutional affiliations.

Ready to submit your research? Choose BMC and benefit from:

- fast, convenient online submission

- thorough peer review by experienced researchers in your field

- rapid publication on acceptance

- support for research data, including large and complex data types

- gold Open Access which fosters wider collaboration and increased citations

- maximum visibility for your research: over $100 \mathrm{M}$ website views per year

At $B M C$, research is always in progress.

Learn more biomedcentral.com/submissions 